\title{
Review of Laser Therapy in Cardiovascular Diseases
}

\author{
Mersedeh Karvandi*(D) \\ Department of Cardiology, Taleghani Hospital, Shahid Beheshti University of Medical Sciences, Tehran, IR Iran
}

\author{
*Correspondence to \\ Mersedeh Karvandi, Email: \\ mc_karvandi@sbmu.ac.ir
}

Received: 13 November, 2020 Accepted: 15 March, 2021 Published online September 26 2021

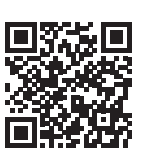

\begin{abstract}
Introduction: In recent years, there has been a rise in laser therapy for the treatment of cardiovascular diseases.

Methods: This paper attempted to represent recent advances in laser therapy in cardiovascular tissue repairs. Three standard techniques have been explicitly described here in cardiovascular tissue repairs by laser.

Results: One of the advantages of using laser therapy in cardiovascular diseases is its noninvasiveness. It also reduces the treatment process pain and prevents massive surgical incisions and bleeding throughout the operation. Laser therapy can ensure an alternative method to treat the ischemic region of the heart and creating anastomosis of vessels.

Conclusion: With professional technologies and endoscopic surgery method development, the role of using lasers has become much more precise and more transparent in cardiovascular diseases.

Keywords: Laser therapy, Cardiovascular tissue repairs, Transmyocardial laser revascularization; Anastomosis; Laser angioplasty
\end{abstract}

\section{Introduction}

Globally, cardiovascular diseases are a significant reason for death. Comprising this with all damages of the cardiovascular systems is roughly distinct. The conventional medical model frequently pursues to treat cardiovascular diseases with medications or surgically bypass or reconstruct obstructed vessels by angioplasty. These procedures were demonstrated to be highly worthwhile that protected numerous survivals. However, medication therapy may be expensive and enduring, which brings the risk of side effects with little or nothing for essential well-being and recovery. Similarly, angioplasty or surgical tasks are invasive techniques that involve side effects and threats.

Laser therapy may redevelop tissues, motivates organic role, reduces infection, and lightens discomfort. It's worth and care are increasingly well known in the management of the cardiovascular diseases of numerous varieties.

Laser is an abbreviation for "Light Amplification by Stimulated Emission of Radiation." It has characteristics of monochromaticity, consistency, directivity, short discrepancy, and intensity. ${ }^{1}$ With starting to use lasers in medicine and laser analysis findings, a valuable claim of spiral therapeutic and diminish ache was recognized. Still, this skill persisted in provoking satisfaction as a result of bleak considerate machinery and quantity reaction., ${ }^{2,3}$ Function and efficiency comprehension, unlike trials, were accomplished to control the laser ray effects at the cellular and tissue levels. The laser beam differs from the usual light due to its wavelength, hence called monochromatic. When passed through a prism, laser ray does not split into several colors, unlike conventional beam. Therefore, noting the laser item is vital, with extreme concentration at an assumed wavelength due to which supreme radioactivity is produced, and concentration sprays to zero at other wavelengths other than the extreme. ${ }^{4}$

A laser beam can be captivated, reproduced, dispersed, or spread upon a tissue interface. A mixture of these events naturally arises a few times, of which the remaining result marks the laser influence that differs according to the laser specifications. Consistent with the GrotthusDraper principle, laser energy must be immersed in causing any biotic effect on the tissue. Immersion is the alteration of beaming light force to a changed force form, typically into heat. It is only the beam that is engrossed to yield the anticipated effect on the tissue. The laser beam interface with the tissue has a common role in the laser wavelength, and it parallels the explicit immersion range of the focused chromosphere. ${ }^{5}$

Furthermore, suitable laser wavelength assortment has to interpret the complexity of the marking assembly in the tissue, as extended wavelengths tend to have more considerable diffusion depth. ${ }^{6}$ This article aimed to represent recent advances in laser therapy for cardiovascular tissue repairs. The use of lasers in endoscopic cardiovascular surgeries, repairing heart 
valves, clogging valve leaks, repairing muscle tissue, and laser sutures during non-invasive operations are particularly noteworthy.

\section{Methods}

In this section, we will discuss the methods of performing three main techniques in the treatment of cardiovascular diseases, namely transmyocardial laser revascularization (TMLR), laser vascular anastomosis, and laser angioplasty, and according to the experiences that exist in the field of these measures, we will review their summary.

\section{Transmyocardial Laser Revascularization for End-Stage Ischemic Heart Diseases}

In the TMLR procedure, tiny punctures are created in the patient's heart muscles from inside the cavities with lasers to improve the blood flow oxygenation of the tissues from inside the heart instead of obstructed vessels (Figure 1).

The TMLR is empirically and clinically done by carbon dioxide laser. The principle behind this method is to source the extra arterial blood from the left ventricular cavity into the ischemic region of the myocardium. An insignificant tissue response was meticulously accepted in the recently generated laser conduits. It is shown that the created ducts with a diameter of about $0.2 \mathrm{~mm}$ remain open for a long time and perform tissue oxygenation. These results revealed the achievability of durable patency of laser conduits and their possible medical use. ${ }^{7}$

Revasculation by coronary artery bypass grafting $(\mathrm{CABG})$ or angioplasty is required, and nothing else is sufficient for patients suffering from ischemic heart disease. Still, where it could not be practical or technically feasible for any reason, myocardial revascularization by laser or TMLR might be suggested. ${ }^{8}$

Mirhoseini et al made laser canals, using carbon dioxide, in the kinetic and dyskinetic parts of the left ventricular myocardium and instantaneously implemented CABG in all patients and reported acceptable and good results. ${ }^{9,10}$ In their series, they choose cases with end-stage coronary artery illness, for whom percutaneous coronary intervention and CABG cannot be performed due to

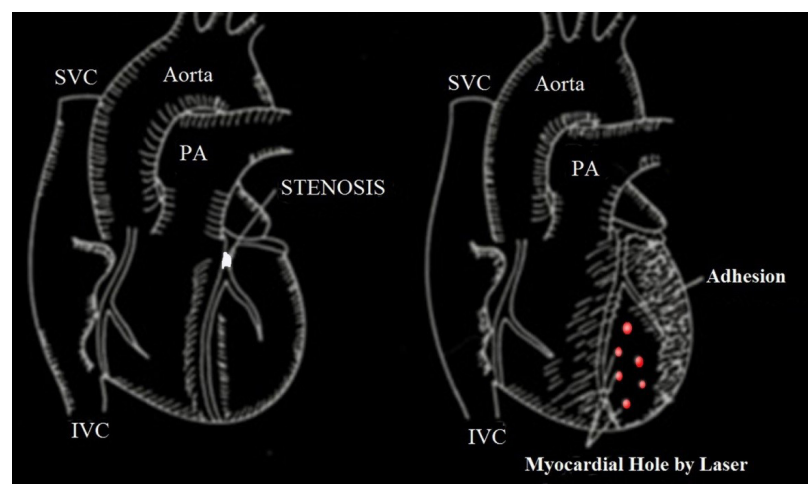

Figure 1. Myocardial Punctures (Red Holes) by Laser in the Ischemic Area. diffuse stenosis and small-caliber coronary arteries. ${ }^{11}$

Various exceptional advantages exist in TMLR:

1. No necessity of extracorporeal circulation.

2. Stress-free work-on and short operating time.

3. Lower costs.

4. Quick body refurbishment.

5. Effectually affordable. ${ }^{12}$

Subsequent studies on this method have shown that TMLR is more effective in relieving the symptoms of angina pectoris in patients and may not have a favorable effect on other cardiac indices. It has been ruled out that angina is only caused by infarction on the foundation of echocardiography and radionuclide data. The more significant incidence of myocardial infarction $(15.0 \%$ vs. $8.9 \%)$, heart failure ( $27 \%$ vs. $11 \%)$, and raised serum creatinine kinase (>1095 IU/L in $50 \%$ of patients) after TMLR showed imperative myocardial damage, which has durable complications. ${ }^{13,14}$

The information gathered from the function of the heart muscles after TMLR is also a little distressing. Echocardiography exhibited that $27 \%$ of patients who underwent TMLR had a significant reduction in the left ventricular function related with $11 \%$ of the medically cured group $(P<0.0001)$. Therefore, echocardiographic observations after TMLR can be a valuable strategy for correct therapeutic results. ${ }^{15}$

\section{Laser Vascular Anastomosis}

Laser vascular anastomosis has long been considered. Extensive studies have been conducted in this field, and finally, the appropriate technique is performed in research cases. The association between the output and the X-ray time of a carbon dioxide laser was considered along with the laser-tissue response in the initial testing. Inflammation, disturbance, and evaporation of the flexible strands of the aorta could be created in percentage to the laser output if the laser productivity of 100 milliwatt $(\mathrm{mW})$ was nonstop illuminated on the matching point for $>10$ seconds. The peak laser yield was 20-40 MW and 6-12 s/mm for vascular anastomosis of lesser-caliber vessels in the margins. ${ }^{16-18}$ Side-to-side, end-to-side, and end-to-end anastomosis at the position of the femoral arteries and veins or the carotid arteries and veins was accomplished by a truncated energy carbon dioxide laser (Figure 2).

The best diameter for vessels to be anastomosed by laser is from 2 to $10 \mathrm{~mm}$. The notched ends of the vessels are attached with Stop-over sutures of 5-0 monofilament suture material to firmly held the vessel edges in place. Sometimes the posterior wall of the femoral artery and its vein was sutured in the conformist procedure by 5-0 suture supplies, and spots of anastomosed by laser were minutely inspected as a controller. The anterior wall was anastomosed by squat energy carbon dioxide (20-40 $\mathrm{mW}$ ) for $6-12 \mathrm{~s} / \mathrm{mm} .{ }^{19}$ The concentrated laser ray was utilized 


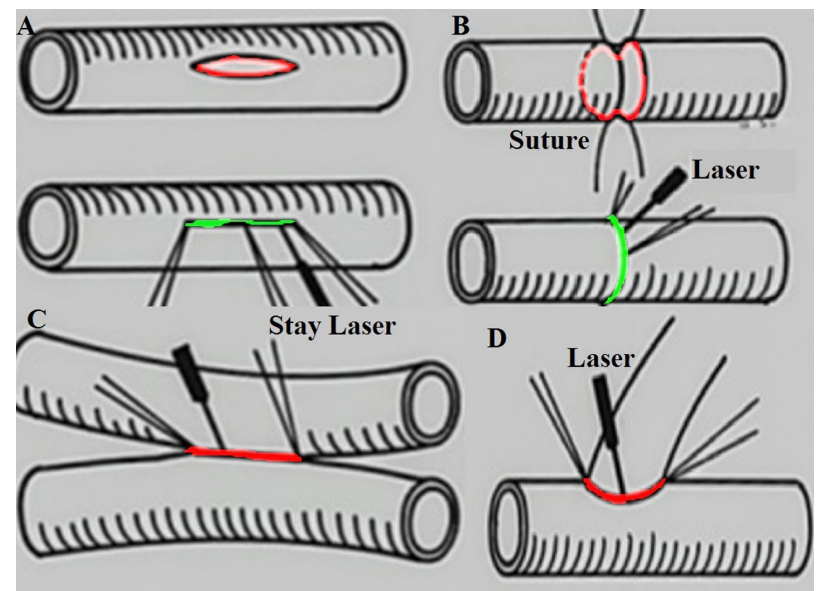

Figure 2. (A-D): A Cross-connection Between the Adjacent Channels by Laser Sutures.

and progressed very gradually to the anastomosed line. The distance between break sutures was preserved at no further than $5 \mathrm{~mm} .{ }^{20}$

Two key facts were considered in finalizing vascular anastomosis. One is situated near the border of the vessels fitted with certain satisfactory stop-over sutures. The distance between break stitches requires to be fewer than $5 \mathrm{~mm}$. An additional one was to emphasize the light ray on the anastomosed route. At this moment, the light ray must be stimulated repetitively, little by little. The Laser beam has to be persistent until the color of the lengthwise anastomosed mark modifies to lead-black or blackbrown. ${ }^{21}$

\section{Laser Angioplasty for Cardiovascular Disease}

The practicality of laser angioplasty might be established in the surgical tasks. In surgery, different kinds of lasers are extensively used in the academic world. ${ }^{22-28}$ An argon laser is used to evaporate the atherosclerotic signs.

Through laser angioplasty, the usage of an angiography scope is unavoidable to detect arterial calcifications. Laser shots are nonstop to remove atherosclerotic plaques under angioscopic supervision until an extensive opening of the vessel thrombus is noticed ${ }^{29}$ (Figure 3 ).

In laser angioplasty, angiography scope and intravascular ultrasound steerage remain necessary to calculate the physical appearances of the athermanous signs and the arterial wall earlier and once during the laser therapy. Integrating computed tomography and echocardiography images $^{30}$ during this procedure is very useful in guiding the laser into the right site. Infrequently, the endoscopic ally may illustrate that immediate and far end parts stayed collected of constricted athermanous signs, or the intermediate slice was not obstructed or occupied with renewed tumor. Based on medical experiences, laser angioplasty should be counseled to exclude or decrease the constricted or congested variations of tiny sections among $10 \mathrm{~cm}$ in the extent of a marginal pathway and needs a supplementary balloon angioplasty. ${ }^{31}$

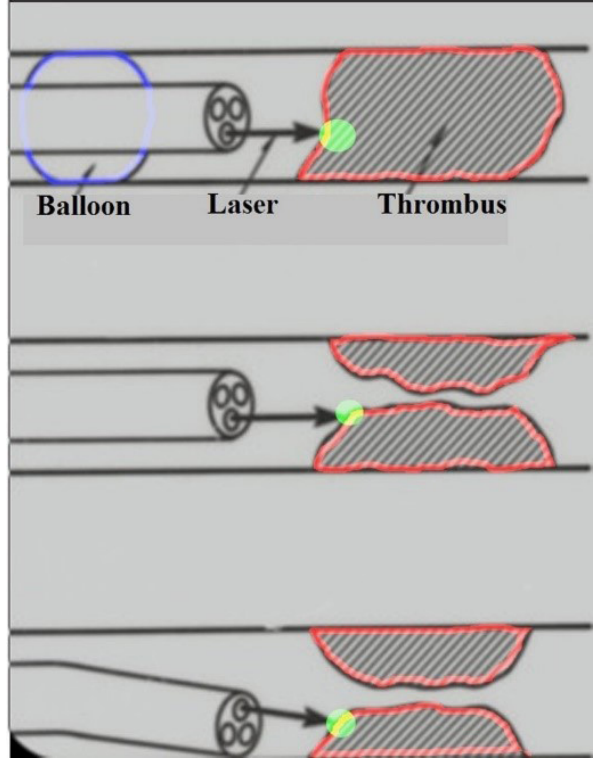

Figure 3. Laser Angioplasty to Eliminate Atherosclerotic Plaques.

\section{Results}

The use of lasers in the treatment of cardiovascular diseases can include the following advantages:

1. Painless treatment.

2. Extremely active for many diseases and conditions.

3. Diminishes the need for pharmaceuticals.

4. Reinstates normal range of motion and physical function soon.

5. Minimal-invasive.

6. Non-toxic.

7. No known adverse effects.

8. No drug communications.

9. Other varieties of surgical interventions are not required.

10. Affordable treatment substitutes for patients who are not responsive to other therapies.

\section{Discussion}

With the advancement of progressive technologies in robotic heart surgeries and minimally invasive surgeries, the use of laser techniques observed in surgery and laser anastomosis will significantly improve damaged tissue repair, especially in closing the leaks around the annulus of the mitral valve, thereby closing it. ${ }^{7,8}$ Closing the ventricular septal disorders or atrial septal disorders by the laser mechanism will make significant progress. It will effectively repair damaged tissues and help understand the physics and means of its proper usage. ${ }^{10}$

The use of lasers in the cardiovascular disorders has advantages like painless treatment, extremely active for many diseases and conditions, diminishing the need for pharmaceuticals, early reinstating normal range of motion and physical function, minimal-invasive procedures, non-toxic with minimal adverse effects, no need to other varieties of surgical interventions and serves as an 
affordable treatment substitute for patients who are not responsive to other therapies.

On the other hand, these treatments require expensive equipment and a lot of experience and skills are required to use them. ${ }^{29}$ In general, the use of this technology is expensive. In most clinical cases, there are not enough valid randomized trials to prove the therapeutic effects of laser and they are still in the study phase.

\section{Conclusion}

The laser treatments offered in the treatment of cardiovascular diseases, namely methods TMLR, laser vascular anastomosis and laser angioplasty are all among the new treatment methods, and by conducting more studies on the techniques and their results, we will soon see their progress.

\section{Ethical Considerations}

Not applicable.

\section{Conflict of Interests}

There is no conflict of interest.

\section{References}

1. Azadgoli B, Baker RY. Laser applications in surgery. Ann Transl Med. 2016;4(23):452-. doi: 10.21037/atm.2016.11.51

2. Pascu ML. Laser physics elements to consider for low level laser therapy. Laser Ther. 2000;13(1):114-125. doi:10.5978/ ISLSM.13.114

3. Madi M, Mahmud MM. The evaluation of healing effect of low level laser treatment following gingivectomy. J Basic Appl Sci. 2020; 9:25. doi: 10.1186/s43088-020-00053-z

4. Suan LP, Bidin N, Cherng CJ, Hamid A. Light-based therapy on wound healing: a review. Laser Phys. 2014;24(8):083001. doi: 10.1088/1054-660X/24/8/083001

5. Bard S. Laser History, Physics, and Safety. Aesthet Dermatol Basel Karger. 2014;1:1-17. doi: $10.1159 / 000355038$

6. Sommer AP, Pinheiro AL, Mester AR, Franke RP, Whelan HT. Biostimulatory windows in low-intensity laser activation: lasers, scanners, and NASA's light-emitting diode array system. J Clin Laser Med Surg. 2001;19(1):2933. doi: 10.1089/104454701750066910

7. Horvath KA. Transmyocardial laser revascularization. J Card Surg. 2008;23:266-276. doi: 10.1111/j.15408191.2008.00579.x

8. Briones E, Lacalle JR, Marin-Leon I, Rueda JR. Transmyocardial laser revscularization versus medical therapy for refractory angina. Cochrane Database Syst Rev. 2015;21:CD003712. doi: 10.1002/14651858.CD003712. pub3

9. Mirhoseini M, Shelgikar S, Cayton MM. New concepts in revascularization of the myocardium. Ann Thorac Surg. 1988;45(4):415-420. doi: 10.1016/s0003-4975(98)90015-7

10. Okada M. Transmyocardial laser revascularization
(TMLR): A long way to the first successful clinical application in the world. Ann Thorac Cardiovasc Surg. 1998;4(3):119-124.

11. Okada M, Shimizu K, Ikuta H, Horii H, Nakamura K. A new method of myocardial revascularization by laser. Thorac Cardiovasc Surg. 1991;39(1):1-4. doi: 10.1055/s2007-1013921

12. Bridges CR. Guidelines for the clinical use of transmyocardial laser revascularization. Semin Thorac Cardiovasc Surg. 2006; 18:68-73. doi: 10.1053/j.semtcvs.2005.12.003

13. Burkhoff D, Schmidt S, Schulman SP, Myers J, Resar J, Becker LC, et al. Transmyocardial laser revascularization compared with continued medical therapy for treatment of refractory angina pectoris: a prospective randomized trial. Lancet. 1999;354:885-890. doi: 10.1016/s01406736(99)08113-1

14. Schofield PM, Sharples LD, Caine N, Burns S, Tait S, Wistow T, et al. Transmyocardial laser revascularisation in patients with refractory angina: a randomised controlled trial. Lancet. 1999;353(9152):519-524. doi: 10.1016/s01406736(98)11478-2

15. Cohn JN, Johnson GR, Shabetai R, Loeb H, Tristani $\mathrm{F}$, Rector $\mathrm{T}$, et al. Ejection fraction, peak exercise oxygen consumption, cardiothoracic ratio, ventricular arrhythmias, and plasma norepinephrine as determinants of prognosis in heart failure. Circulation. 1993;87:V15-16.

16. 'Neill AC, Winograd JM, Zeballos JL, Johnson TS, Randolph MA, Bujold KE, et al. Microvascular anastomosis using a photochemical tissue bonding technique. Laser Surg Med. 2007;39(9):716-722. doi: 10.1002/lsm.20548

17. Puca A, Esposito G, Albanese A, Maira G, Rossi F, Pini R. Minimally occlusive laser vascular anastomosis (MOLVA): experimental study. Acta Neurochi. 2009;151:363-368, 2009. doi 10.1007/s00701-009-0219

18. Pabittei DR, Heger M, Beek JF, van Tuijl S, Simonet M, van der Wal AC, et al. Optimization of suture-free laserassisted vessel repair by solder-doped electrospun poly( $\varepsilon$ caprolactone) scaffold. Ann Biomed Eng. 2011;39(1):22334. doi: 10.1007/s10439-010-0157-5.

19. Leclère FMP, Schoofs M, Buys B, Mordon SR. Outcome after $1.9 \mathrm{~mm}$ diode laser assisted anastomosis in reconstructive microsurgery: results in 27 patients. Plast Reconstr Surg. 2010;125:1167-1175. doi: 10.1097/prs.0b013e3181d18173

20. Crocker $M$, Walsh $D$, Epaliyanage $\mathrm{P}$, Tolias CM. Excimer laser assisted non-occlusive cerebral vascular anastomosis (ELANA): review of the first of the UK experience. Br J Neurosurg. 2010;24:148-155. doi:10.3109/02688690903506127

21. Okada M,Yoshida M, Tsuji Y, Horii H. Clinical application of laser treatment for cardiovascular surgery. Laser Ther. 2011;20(3):217-32. doi: 10.5978/islsm.20.217

22. Köster R, Jan Kähler J, Brockhoff C, Münzel T, Meinertz T. Laser coronary angioplasty: history, present and future. Am J Cardiovasc Drugs. 2002; 2(3):197-207. doi: 10.2165/00129784-200202030-00006 
23. Sanborn TA, Faxon DP, Haudenshild CC, Ryan TJ. Experimental angioplasty: circumferencial distribution of laser thermal injury with a laser probe. J Am Coll Cardiol. 1985;5(4):934-938.

24. Cumberland DC, Sanborn TA, Tayler DI, Moore DJ, Welsh CL, Greenfield AJ, et al. Percutaneous laser thermal angioplasty: Initial clinical results with a laser probe in total peripheral artery occlusions. Lancet. 1986; 327(8496):14571459. doi: 10.1016/s0140-6736(86)91498-4.

25. Dietrich EB, Timbadia E, Bahadir I, Coburn K, Zenzen S. Argon laser assisted peripheral angioplasty. Vasc Surg. 1988; 22(2):77-87. doi:10.1177/153857448802200201

26. Okada M. Clinical and experimental studies on laser application for coronary and the peripheral arterial disease. Rev Euro Technol Biomed. 1990;12:27-31.

27. Dietrich EB, Hanafy HM, Santiago OF. Intraoperative coronary excimer laser angioplasty: preliminary clinical experience. Angiology. 1990; 41:777-779.

28. Okada M, Yoshida M, Tsuji Y, Horii H. Laser angioplasty dor peripheral and the coronary artery disease. Angiology. 1990; 42:121-127.

29. Okada M, Yoshida M. Current trends of medical engineering technology. Medical Therapeutic Eng. 1998; 10:208-219.

30. Mohammadi Tofigh A, Karvandi M, Coscas R. Current incidence of peripheral arterial embolism and role of echocardiography. Asian Cardiovasc Thorac Ann. 2008; 16(6):439-43. doi: 10.1177/021849230801600602.

31. Das TS. Excimer laser assisted angioplasty for infrainguinal artery disease. J Endovasc Ther. 2009;16(Suppl II):98-104. doi: 10.1583/08-2655.1 